\title{
Association between omentin-1 and major cardiovascular events after lower extremity endovascular revascularization in diabetic patients: a prospective cohort study
}

Federico Biscetti ${ }^{1,2,3,9^{*}}$ (0), Elisabetta Nardella², Maria Margherita Rando², Andrea Leonardo Cecchini², Flavia Angelini ${ }^{3}$, Alessandro Cina ${ }^{4}$, Roberto lezzi ${ }^{4}$, Marco Filipponi ${ }^{5}$, Angelo Santoliquido 1,6,7, Dario Pitocco 1,6,8, Raffaele Landolfi, ${ }^{1,2,6}$ and Andrea Flex $x^{1,2,3,6}$

\begin{abstract}
Background: Cardiovascular complications represent the major cause of morbidity and mortality of type 2 diabetes mellitus (T2DM) patients. In particular, peripheral artery disease (PAD) represents a frequent T2DM vascular complication and a risk factor for the development of major adverse cardiovascular events (MACE). Among adipokines, omentin-1 serum levels are reduced in T2DM patients with PAD and are inversely related to disease severity.
\end{abstract}

Objective: To study the relationship between omentin-1 levels, at baseline, with outcomes after endovascular procedures in T2DM patients with PAD and chronic limb-threatening ischemia (CLTI).

Research design and methods: We enrolled for our prospective non-randomized study, 207 T2DM patients with PAD and CLTI, requiring revascularization. Omentin-1 serum levels were collected before revascularization and patients incidence outcomes were evaluated at 1, 3, 6 and 12 months.

Results: Omentin-1 was reduced in patients with more severe disease $(27.24 \pm 4.83$ vs $30.82 \pm 5.48 \mathrm{ng} / \mathrm{mL}, \mathrm{p}<0.001)$. Overall, 84 MACE and 96 major adverse limb events (MALE) occurred during the 12-month follow-up. We observed that omentin-1 levels were lower in patients with MACE (26.02 \pm 4.05 vs $31.33 \pm 5.29 \mathrm{ng} / \mathrm{mL}, \mathrm{p}<0.001)$ and MALE ( $26.67 \pm 4.21$ vs $31.34 \pm 5.54 \mathrm{ng} / \mathrm{mL}, \mathrm{p}<0.001)$. The association between omentin-1, MACE and MALE remained significant after adjusting for major risk factors in a multivariate analysis. Receiver operating characteristics (ROC) curve using omentin-1 levels predicted incidence events (area under the curve $=0.80$ ).

Conclusions: We demonstrated that reduced omentin-1 levels, at baseline, are related with worse vascular outcomes in T2DM patients with PAD and CLTI undergoing an endovascular procedure.

Keywords: Type 2 diabetes mellitus, Chronic limb-threatening ischemia, Major adverse limb events, Outcome prediction, Omentin-1

${ }^{*}$ Correspondence: f.biscetti@gmail.com

${ }^{1}$ Fondazione Policlinico Universitario A. Gemelli IRCCS, Rome, Italy

Full list of author information is available at the end of the article

\section{Background}

Peripheral artery disease (PAD) represents one of the most frequent vascular complications of type 2 diabetes mellitus (T2DM) [1]. PAD is also an independent risk factor for further cardiovascular complications in T2DM patients [2]. Treatment of PAD includes the reduction of

(c) The Author(s) 2020. This article is licensed under a Creative Commons Attribution 4.0 International License, which permits use, sharing, adaptation, distribution and reproduction in any medium or format, as long as you give appropriate credit to the original author(s) and the source, provide a link to the Creative Commons licence, and indicate if changes were made. The images or other third party material in this article are included in the article's Creative Commons licence, unless indicated otherwise in a credit line to the material. If material is not included in the article's Creative Commons licence and your intended use is not permitted by statutory regulation or exceeds the permitted use, you will need to obtain permission directly from the copyright holder. To view a copy of this licence, visit http://creativecommons.org/licenses/by/4.0/. The Creative Commons Public Domain Dedication waiver (http://creativecommons.org/ publicdomain/zero/1.0/) applies to the data made available in this article, unless otherwise stated in a credit line to the data. 
modifiable risk factors, such as smoking and obesity and the improvement of medical therapy for diabetes, high blood pressure and dyslipidemia [3]. Despite the best medical cures, several patients aggravate and experience chronic limb-threatening ischemia (CLTI), lower limb ulcers and amputations [2]. In the case of CLTI, lower limb revascularization (LER) is suggested. Among LER approaches, endovascular revascularization is an effective option [4]. Notwithstanding vascular centers' expertise, numerous treated patients experience remarkably different outcomes [5]. In fact, after LER, a considerable percentage of individuals develop major adverse cardiovascular events (MACE) or major adverse limb events (MALE) [4]. For this reason, biomarkers are necessary to stratify the risk of these patients and to design a more effective follow-up.

Among possible factors involved in atherosclerosis and vascular complications of T2DM, adipokines have been discussed in numerous reports and significant evidence is available [6]. Among the adipokines, omentin-1 is a protein closely associated to obesity, visceral fat and diabetes [7-11]. In particular, omentin-1 levels are negatively related to insulin resistance [9] and coronary artery disease (CAD) [12-14]. Moreover, omentin-1 seems to have beneficial effects in obese patients at higher cardiovascular risk [15]. Furthermore, we recently demonstrated that omentin-1 levels are inversely correlated to the presence of PAD and disease severity in T2DM patients [16].

Given the existing data, we postulate that the occurrence of cardiovascular events after LER may dependent on basal omentin-1 levels.

The purpose of this study is to assess the relationship between omentin-1 levels and vascular outcomes, in particular MACE and MALE, after endovascular revascularization in T2DM patients with PAD and CLTI.

\section{Research design and methods Study design}

This study was designed as a prospective non-randomized study to verify the relationship between omentin-1 levels and the incidence of MACE and MALE after LER performed in T2DM patients with PAD and CLTI. The study was approved by the Ethics Committee of the Fondazione Policlinico Universitario A. Gemelli IRCCS and adhered to the principles of the Declaration of Helsinki. All the individuals agreed to participate in the study and provided informed consent.

\section{Study population and clinical assessment}

Overall, 207 T2DM patients with PAD and CLTI belowthe-knee were included and followed for the entire duration of the study. Patients were consecutively enrolled during a period between 30/05/2018 and $15 / 04 / 2019$ at the Fondazione Policlinico Universitario A. Gemelli IRCCS, Rome, Italy. Inclusion criteria were age of 18 years or older, T2DM diagnosis [16] at least 1 year prior to the study, ankle/brachial index (ABI) lower than 0.80 , peripheral artery stenosis greater than $50 \%$ documented by duplex ultrasound (US), presence of PAD at Rutherford category 4 or 5 , presence of CLTI requiring endovascular treatment, no infections at present or in the previous month. In case of diabetic foot ulcers, additional criteria would be no local signs of infection and no need for antibiotic therapy. The wound, ischemia, foot infection (WIfI) classification system was used to stratify T2DM patients with foot ulcers. Radiological examination was performed, according to clinical judgment, to exclude osteomyelitis. Exclusion criteria were lower limb endovascular treatment or previous lower limb bypass surgery within the past 3 months, diabetic peripheral neuropathy, systemic steroid use or a prior history of use in the previous month, pregnancy, active cancer, life expectancy $<12$ months, known liver disease with a functional status of B or above according to the Child-Pugh classification, congenital or acquired thrombophilia and active autoimmune disease [17].

All subjects were studied to rule out the presence of diabetic peripheral neuropathy, as previously described $[18,19]$. Briefly, an assessment of vibration perception threshold was performed with a biothesiometer. All diabetic patients received a definite diagnosis of peripheral neuropathy with a Neuropathy Disability Score $>5$ and a pathological conduction velocity. Autonomic neuropathy was diagnosed according to the standardized procedure of Ewing and Clarke, including four cardiovascular autonomic tests [20].

For all patients, additional clinical data was collected, including age, body mass index (BMI), history of cardiovascular diseases (CAD), cerebrovascular disease (CVD), hypertension, hypercholesterolemia, smoking, renal failure [defined as an estimated glomerular filtration rate $(\mathrm{eGRF})<60 \mathrm{~mL} / \mathrm{min}]$. All patients underwent a complete US peripheral vascular evaluation, and PAD was defined according to the criteria established by the ad hoc Committee on Reporting Standards of the Society for Vascular Surgery and the International Society for Cardiovascular Surgery [21]. In subjects with an ABI of 1.40 or more (uncertain arterial calcification), US evaluation was performed to assess significant stenosis of the peripheral arteries [22].

At the time of enrollment, all patients were on statin treatment, and they continued therapy after LER, aiming at low-density lipoprotein cholesterol (LDL-C) levels less than $70 \mathrm{mg} / \mathrm{dl}$. 


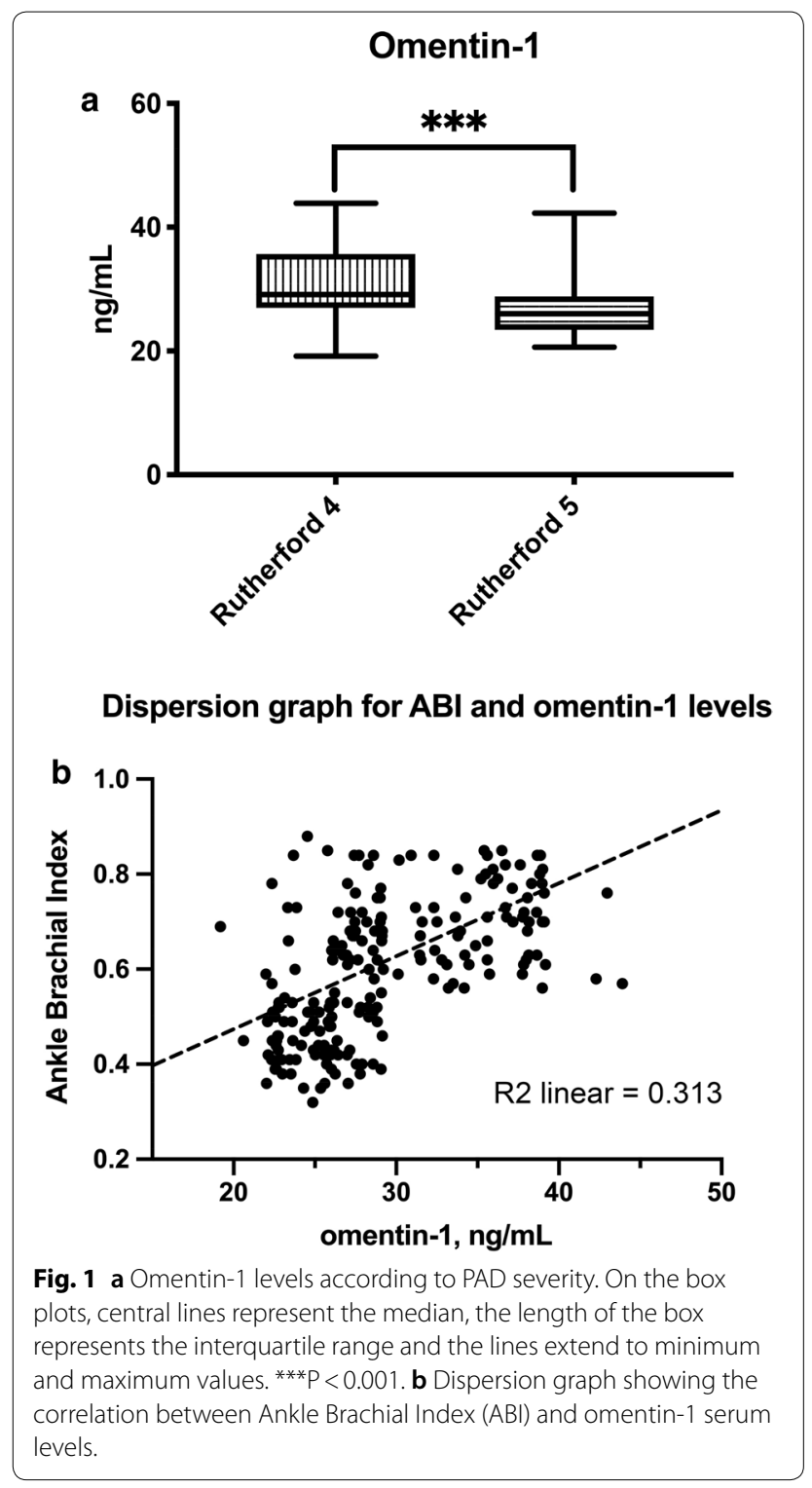

Patients were on single antiplatelet therapy, which was modified to dual antiplatelet therapy after LER for the following month.

\section{Revascularization treatment and follow-up}

Angiography of the lower limb arteries, balloon angioplasty and, if indicated, stenting were performed as previously described [23]. The procedure was successful if the residual arterial stenosis was less than 30\% [24]. No major complications, defined according to the definitions of the Society of Interventional Radiology [24], were observed. Of the 224 patients who underwent LER, 17 (7.6\%) had a
Table 1 Demographic characteristics of the study cohort at baseline

\begin{tabular}{|c|c|}
\hline Number of patients & 207 \\
\hline Age, years (SD) & $75.0(9.0)$ \\
\hline Men, n (\%) & $144(69.6)$ \\
\hline Women, n (\%) & $63(30.4)$ \\
\hline Diabetes duration, years (SD) & $11.4(0.8)$ \\
\hline $\mathrm{BMI}, \mathrm{kg} / \mathrm{m}^{2}(\mathrm{SD})$ & $26.7(0.6)$ \\
\hline Oral antidiabetic agents, n (\%) & $92(44.4)$ \\
\hline Insulin, n (\%) & $152(73.4)$ \\
\hline High blood pressure, n (\%) & $144(69.6)$ \\
\hline Hypercholesterolemia, n (\%) & $113(54.6)$ \\
\hline \multicolumn{2}{|l|}{ Smoking status } \\
\hline Never smoked, n (\%) & $57(27.5)$ \\
\hline Past smoker, n (\%) & $23(11.1)$ \\
\hline Current smoker, n (\%) & $127(61.4)$ \\
\hline $\mathrm{ABI}(\mathrm{SD})$ & $0.39(0.07)$ \\
\hline \multicolumn{2}{|l|}{ Rutherford staging } \\
\hline Stage 4, n (\%) & $112(54.1)$ \\
\hline Stage $5, \mathrm{n}(\%)$ & 95 (45.9) \\
\hline \multicolumn{2}{|l|}{ WIfl classification } \\
\hline WIfl 010, n (\%) & $63(30.4)$ \\
\hline WIfl 020, n (\%) & $53(25.6)$ \\
\hline WIfl 110, n (\%) & $49(23.7)$ \\
\hline WIfl 120, n (\%) & $42(20.3)$ \\
\hline Previous coronary artery disease, $\mathrm{n}(\%)$ & $95(45.9)$ \\
\hline Previous cerebrovascular disease, $\mathrm{n}(\%)$ & $101(48.8)$ \\
\hline Total cholesterol, mg/dL (SD) & $219.3(22.3)$ \\
\hline LDL cholesterol, mg/dL (SD) & $112.7(15.5)$ \\
\hline Triglycerides, mg/dL (SD) & $172.4(8.5)$ \\
\hline Glucose, mg/dL (SD) & $128.0(9.7)$ \\
\hline $\mathrm{HbA1C}, \%(S D)$ & $8.9(0.7)$ \\
\hline $\mathrm{eGFR}, \mathrm{mL} / \mathrm{min} / 1.73 \mathrm{~m}^{2}$ (SD) & $72.8(10.6)$ \\
\hline Omentin-1, ng/mL (SD) & $29.2(5.4)$ \\
\hline
\end{tabular}

Data are reported as means (standard deviation) for continuous variables and numbers (percentages) for categorical variables. BMI Body Mass Index, $A B I$ Ankle Brachial Index, WIfI Wound, ischemia, foot infection, LDL low-density lipoprotein, eGFR estimated glomerular filtration rate

poor primary outcome and were excluded from the study follow-up.

For the follow-up, patients were evaluated 1, 3, 6 and 12 months after the LER to assess incidence of MACE and MALE. MACE were defined as composite of myocardial infarction, stroke and cardiovascular death. MALE were defined as composite of acute limb ischemia, major vascular amputations, limb-threatening ischemia leading to urgent revascularization. 

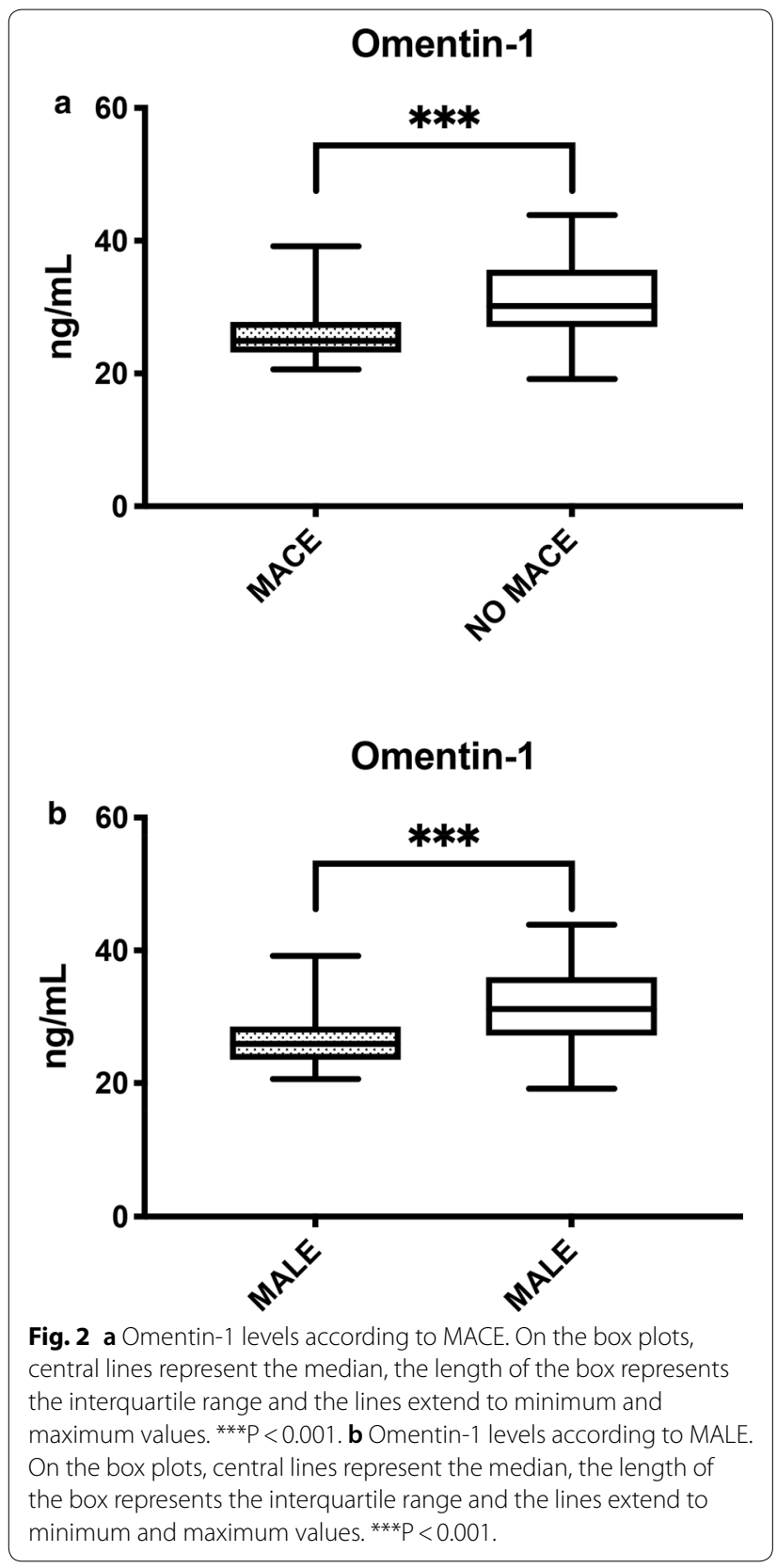

\section{Blood sampling procedures and biochemical assays}

Blood sampling of patients was performed at baseline, just before the LER, after an overnight fast. Fasting glucose, serum creatinine, total cholesterol, LDL-C, triglycerides, and glycated hemoglobin, were determined. Renal function was calculated using eGFR, which was performed using the modification of diet in renal disease formula. Serum was prepared by centrifugation of blood samples, which was stored at $-80^{\circ} \mathrm{C}$ until assayed. Serum omentin- 1 levels were determined by a commercially available ELISA kit (E-EL-H2028, Elabscience) according to its protocol. The intra- and inter-assay coefficients of variation were 3.5 and $10.5 \%$, respectively. The sensitivity, defined as the mean $\pm 3 \mathrm{SD}$ of the 0 standard, was calculated to be $0.15 \mathrm{pmol} / \mathrm{mL}$. For each patient, the serum levels were measured twice, and the results were averaged.

\section{Statistical analysis}

Data was summarized as means (standard deviations) for continuous variables and counts (percentages) for categorical variables. Demographic and clinical data of the groups were compared using Chi-square and t-test. Omentin-1 serum levels were compared with MannWhitney, Kruskal-Wallis and Dunn's Multiple Comparison, when appropriate. A log transformation was applied to the not normally distributed variables prior to performing further analysis. A multivariate stepwise logistic regression analysis was performed, adjusted for traditional risk factors and omentin-1 levels. The area under the receiver operating characteristics (ROC) curve was calculated to test the predictive discrimination of MACE. The freedom from MACE according to the quartiles of serum omentin-1 was estimated using the Kaplan-Meier method and compared using the Log-Rank test. All analyses were performed using STATA version 14.0 for MacOS (Statistics/Data Analysis, Stata Corporation, College Station, TX, USA) and SPSS version 25.0 for MacOS (IBM Corporation, Armonk, NY, USA). Statistical significance was established at $\mathrm{p}<0.05$.

\section{Results}

Demographic and clinical characteristics

Overall, 207 T2DM patients with PAD and CLTI were followed for the entire duration of the study. The mean age (SD) of patients was 75 (9.0) years. Of these, 144 (69.6\%) were males. Patients had in average 11.4 (0.8) years T2DM. Complete clinical features are shown in Table 1. Patients with more severe PAD had lower serum omentin-1 levels than those with less severe PAD $(27.24 \pm 4.83$ vs $30.82 \pm 5.47 \mathrm{ng} / \mathrm{mL}, \mathrm{p}<0.001)$ (Fig. 1a). In addition, a strong positive correlation between omentin-1 levels and ABI were noted (Fig. 1b).

\section{Serum omentin-1 and risk of MACE at 12 months}

During the 12-month follow-up period, 84 (40.6\%) patients experienced MACE after LER. Complete clinical data from patients with MACE and without MACE are shown in Table 2. Considering baseline omentin-1 levels, patients with MACE had lower baseline serum levels $(26.02 \pm 4.05$ vs $31.33 \pm 5.29 \mathrm{ng} / \mathrm{mL}, \mathrm{p}<0.001)$ (Fig. 2a). Of these, 16 (7.7\%) patients died (Fig. 3a) and had lower serum levels than survivors $(23.71 \pm 1.49$ vs $29.63 \pm 5.44 \mathrm{ng} / \mathrm{mL}, \mathrm{p}<0.001)$. Furthermore, $44(21.3 \%)$ 


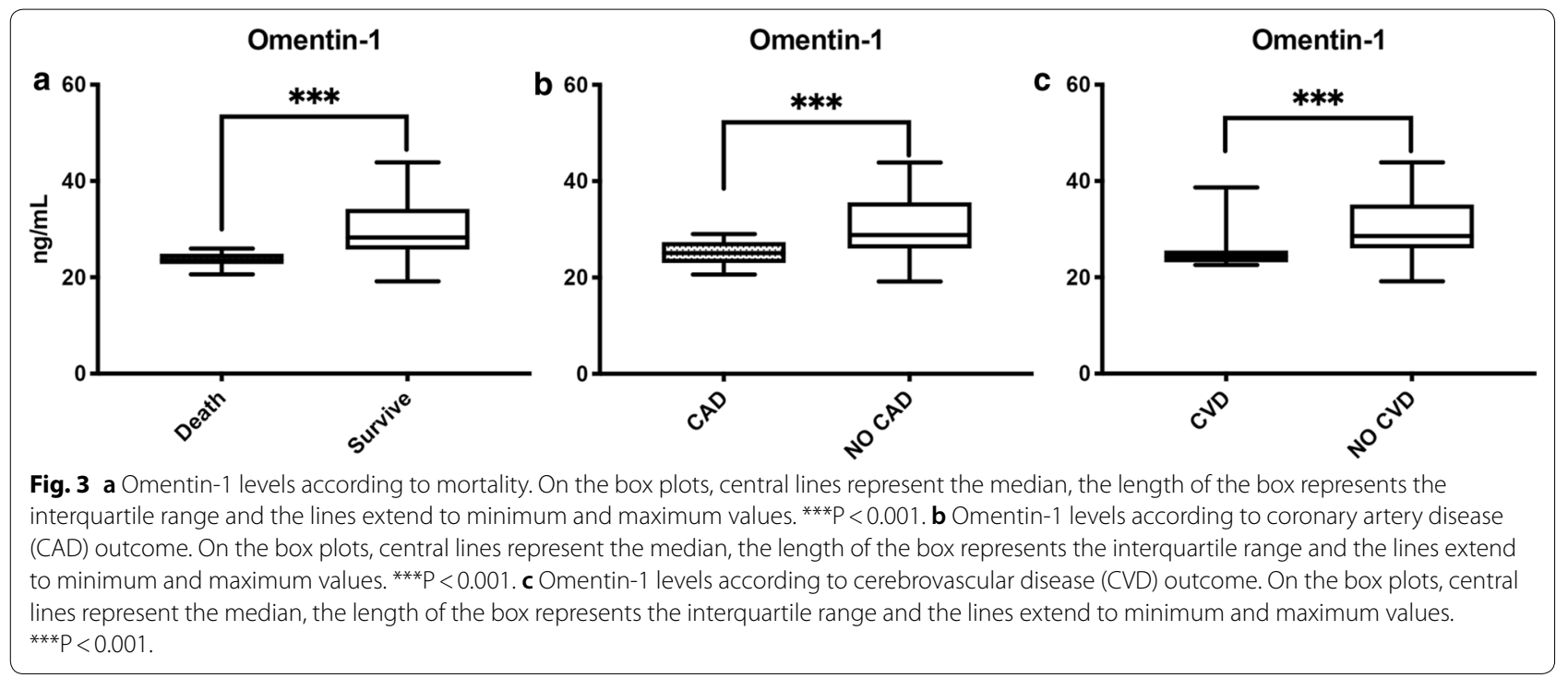

Table 2 Demographic and clinical data of diabetic subjects with and without MACE

\begin{tabular}{|c|c|c|c|}
\hline & NO MACE $(n=123)$ & MACE $(n=84)$ & $p$ value \\
\hline Age, years & 75.244 & 74.584 & 0.606 \\
\hline Men:women, $\mathrm{n}$ & $79: 44$ & $65: 19$ & 0.043 \\
\hline $\mathrm{BMI}, \mathrm{kg} / \mathrm{m}^{2}$ & 26.712 & 26.729 & 0.858 \\
\hline $\begin{array}{l}\text { Diabetes duration, } \\
\text { years }\end{array}$ & 11.463 & 11.373 & 0.463 \\
\hline HBP, n (\%) & $81(65.9)$ & $63(75.0)$ & 0.160 \\
\hline $\mathrm{HCHOL}, \mathrm{n}(\%)$ & $64(52,0)$ & $49(58.3)$ & 0.371 \\
\hline CAD, n (\%) & $55(44.7)$ & $40(47.6)$ & 0.681 \\
\hline CVD, n (\%) & $59(48.0)$ & $42(52.0)$ & 0.774 \\
\hline Current smokers, n (\%) & $61(49.6)$ & 66 (78.6) & $<0.001$ \\
\hline Past smokers, n (\%) & $10(8.1)$ & $13(15.5)$ & 0.099 \\
\hline Never smoked, n (\%) & $52(42.3)$ & $5(6.0)$ & $<0.001$ \\
\hline Ankle Brachial Index & 0.651 & 0.528 & $<0.001$ \\
\hline $\begin{array}{l}\text { Total cholesterol, mg/ } \\
\text { dL }\end{array}$ & 215.588 & 224.638 & 0.00 \\
\hline $\begin{array}{l}\text { LDL cholesterol, mg/ } \\
\text { dL }\end{array}$ & 107.097 & 120.691 & $<0.001$ \\
\hline Triglycerides, mg/dL & 172.826 & 171.779 & 0.38 \\
\hline Glucose, mg/dL & 128.114 & 127.823 & 0.83 \\
\hline $\mathrm{HbA} 1 \mathrm{C}, \%$ & 8.832 & 8.974 & 0.15 \\
\hline eGFR mL/min/1.73 m² & 73.096 & 72.459 & 0.67 \\
\hline Omentin-1 ng/mL & 31.326 & 26.024 & $<0.001$ \\
\hline
\end{tabular}

$B M I$ Body Mass Index, HBP High Blood Pression, HCHOL Hypercholesterolemia, CAD Coronary Artery Disease, CVD Cerebrovascular Disease, $L D L$ low-density lipoprotein, eGFR estimated glomerular filtration rate. Statistical test performed with Student's t-test or with Chi square test, when appropriate.

patients had a myocardial infarction and had lower omentin-1 levels than patients without CAD $(25.22 \pm 2.35$ vs $30.24 \pm 5.59 \mathrm{ng} / \mathrm{mL}, \mathrm{p}<0.001$ ) (Fig. 3b). Moreover, 35
(16.9\%) individuals had a stroke and lower levels than patients without CVD $(25.06 \pm 3.01$ vs $30.01 \pm 5.49 \mathrm{ng} /$ $\mathrm{mL}, \mathrm{p}<0.001$ ) (Fig. 3c).

The area under the ROC curve to predict the incidence of MACE in T2DM patients, based on omentin-1 levels, was 0.80 (95\% CI 0.74, 0.87) (Fig. 4). The best cut-off value of omentin-1 for prediction of the occurrence of MACE in our population was $<26.23 \mathrm{ng} / \mathrm{mL}$ (Sensitivity 79.7\%, Specificity 70.2\%).

Kaplan-Meier curves showing MACE-free survival according to omentin-1 quartiles are reported in Fig. 5. Omentin-1 quartile curves differed significantly (LogRank $\mathrm{p}<0.001$ ), and patients in the lowest quartile had the highest cumulative incidence of MACE.

The multivariate logistic regression analysis showed that, after adjustments for the cardiovascular risk factors age, male sex, BMI, smoking, hypertension, CAD, CVD, ABI, LDL-C, fasting plasma glucose and glycated hemoglobin, omentin-1 level was an independent determinant for MACE after LER in T2DM patients with PAD and with CLTI $(\mathrm{p}<0.001,95 \%$ CI -0.039 , -0.014 ) (Table 3).

Further multivariable logistic regression analyses demonstrated that omentin-1 level was an independent determinant for the incidence of CAD $(\mathrm{p}=0.001$, 95\% CI $-0.03,-0.007)$ and CVD ( $<<0.001,95 \%$ CI $-0.032,-0.011$ ) (Additional file 1: Tables S2 and S3). Only LDL-C remained an independent determinant for the incidence of death outcome $(\mathrm{p}<0.001,95 \%$ CI $0.003,0.008$ ) (Additional file 1: Table S1). 


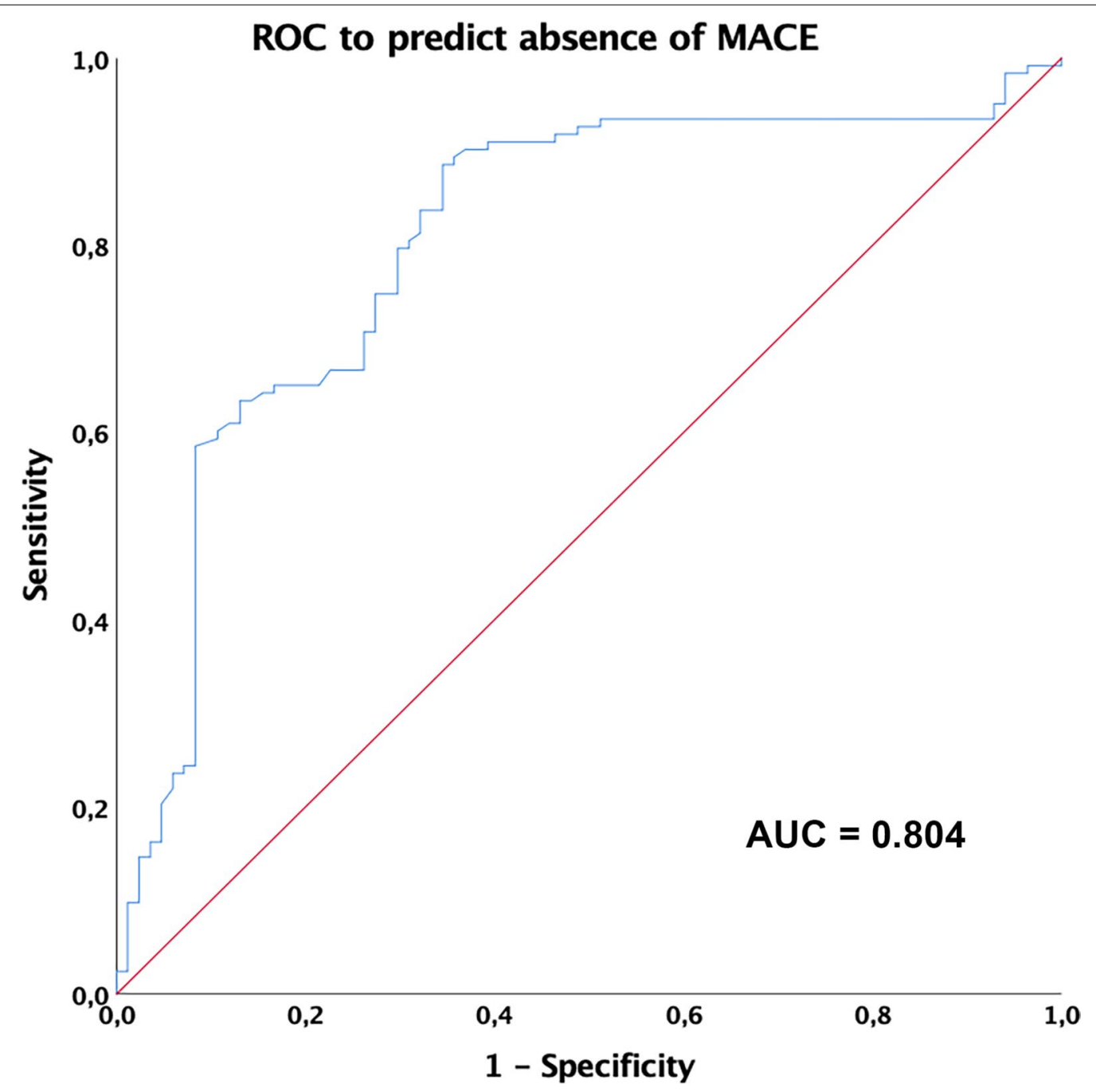

Fig. 4 ROC curve analysis to predict absence of MACE related to omentin-1 levels in T2DM showing an area under the ROC curve of 0.804 $(P<0.001)$

\section{Serum omentin-1 and risk of MALE at 12 months}

During the 12-month follow-up, 96 (46.4\%) patients had MALE following LER. Notably, we observed that omentin-1 levels were lower in patients that developed MALE than those who did not $(26.67 \pm 4.21 \mathrm{vs}$ $31.34 \pm 5.54 \mathrm{ng} / \mathrm{mL}, \mathrm{p}<0.001$ ) (Fig. 2b). In the group of patients who had MALE, smoking status $(\mathrm{p}<0.001)$, ABI $(\mathrm{p}<0.001)$, LDL-C $(\mathrm{p}<0.001)$ and Rutherford staging $(\mathrm{p}<0.001)$ were significantly different from patients without MALE. The remaining clinical and laboratory characteristics are shown in Table 4.

The multivariate logistic regression analysis showed that, after adjustments for traditional cardiovascular risk factors, omentin-1 level was related to incidence of MALE after LER in T2DM patients with PAD and with CLTI ( $<<0.001,95 \%$ CI $-0.041,-0.014)$ (Table 5).

\section{Discussion}

T2DM patients with PAD have a higher risk of cardiovascular complications than T2DM patients without peripheral vascular involvement [2]. Despite multiple therapeutic approaches and multidisciplinary management, definite biomarkers, useful to stratify the risk for T2DM patients with PAD and CLTI are not available [25, 26]. Regarding follow-up after revascularization, even less clear evidence is available [27]. In fact, outcomes after LER vary widely among T2DM patients [4]. Despite similar baseline clinical characteristics-in terms of risk factor control and PAD severity-and the same endovascular approach, some patients do not encounter complications for years while other patients may have complications, even fatal, within a few months [27]. Several potential biomarkers have been proposed, some 


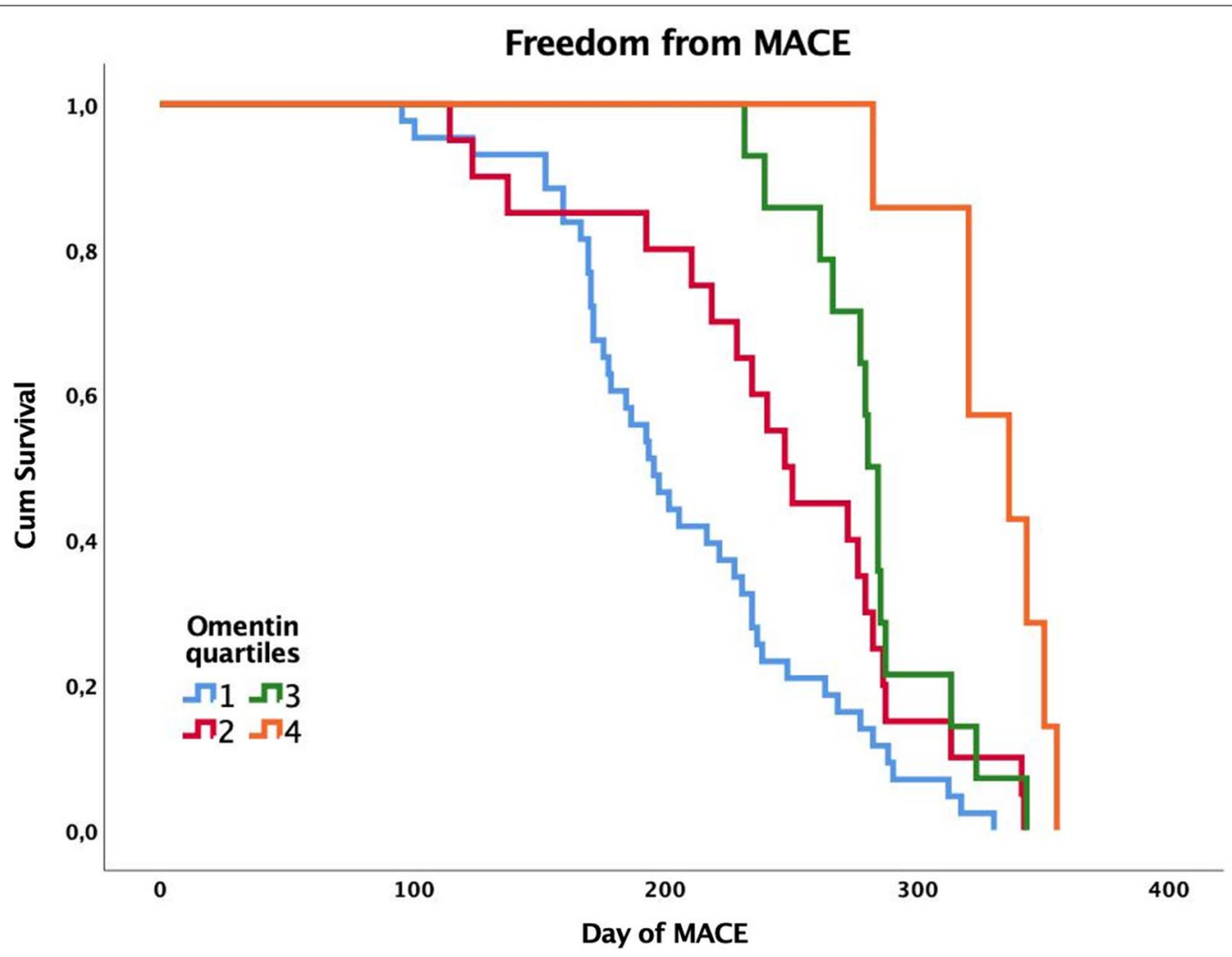

Fig. 5 The freedom from MACE according to the quartiles of serum omentin-1 was estimated using the Kaplan-Meier method and compared using the Log-Rank test $(P<0.001)$. The quartiles of omentin-1 are listed in color code lines. Blue represents the first quartile, red the second, green the third, orange the fourth

Table 3 Multivariable logistic regression for MACE

\begin{tabular}{|c|c|c|c|c|c|c|c|}
\hline & Coef & St.Err & t-value & p-value & {$[95 \%$ Conf } & Interval] & Sig \\
\hline Age & -0.002 & 0.003 & -0.74 & 0.457 & -0.009 & 0.004 & \\
\hline Male sex & -0.044 & 0.070 & -0.63 & 0.528 & -0.182 & 0.093 & \\
\hline $\mathrm{HBP}$ & 0.026 & 0.065 & 0.41 & 0.683 & -0.101 & 0.154 & \\
\hline $\mathrm{HCHOL}$ & 0.038 & 0.059 & 0.65 & 0.516 & -0.078 & 0.155 & \\
\hline CAD & 0.073 & 0.059 & 1.23 & 0.219 & -0.044 & 0.190 & \\
\hline CVD & -0.011 & 0.060 & -0.19 & 0.851 & -0.130 & 0.107 & \\
\hline Current smokers & -0.040 & 0.097 & -0.41 & 0.683 & -0.232 & 0.152 & \\
\hline Past smokers & 0.000 & & & & & & \\
\hline Never smoked & -0.296 & 0.111 & -2.67 & 0.008 & -0.514 & -0.077 & $* * *$ \\
\hline $\mathrm{ABI}$ & -0.209 & 0.280 & -0.75 & 0.456 & -0.762 & 0.343 & \\
\hline LDL-C & 0.006 & 0.002 & 2.59 & 0.010 & 0.001 & 0.011 & $* *$ \\
\hline FPG & 0.003 & 0.003 & 0.87 & 0.384 & -0.003 & 0.009 & \\
\hline $\mathrm{HbA} 1 \mathrm{C}$ & 0.046 & 0.042 & 1.07 & 0.284 & -0.038 & 0.129 & \\
\hline Omentin-1 & -0.025 & 0.007 & -3.70 & $<0.001$ & -0.038 & -0.012 & $* * *$ \\
\hline Constant & 0.058 & 0.719 & 0.08 & 0.936 & -1.360 & 1.476 & \\
\hline Mean dependent var & 0.406 & & SD dependent var & 0.492 & & & \\
\hline R-squared & 0.349 & & Number of obs & 207.000 & & & \\
\hline F-test & 7.942 & & Prob $>F$ & 0.000 & & & \\
\hline Akaike crit. (AIC) & 232.299 & & Bayesian crit. (BIC) & 278.957 & & & \\
\hline
\end{tabular}

${ }^{* * *} p<0.01,{ }^{* *} p<0.05,{ }^{*} p<0.1$ 
Table 4 Demographic and clinical data of diabetic subjects with and without MALE

\begin{tabular}{|c|c|c|c|}
\hline & NO MALE $(n=111)$ & MALE $(n=96)$ & $\mathrm{p}$ value \\
\hline Age, years & 74.901 & 75.062 & 0.898 \\
\hline Men:women, $\mathrm{n}$ & $68: 43$ & $76: 20$ & 0.005 \\
\hline $\mathrm{BMI}, \mathrm{kg} / \mathrm{m}^{2}$ & 26.757 & 26.675 & 0.364 \\
\hline $\begin{array}{l}\text { Diabetes duration, } \\
\text { years }\end{array}$ & 11.486 & 11.357 & 0.289 \\
\hline HBP, n (\%) & $73(65,8)$ & $71(74.0)$ & 0.201 \\
\hline HCHOL, n (\%) & $59(53.2)$ & $54(56.3)$ & 0.655 \\
\hline CAD, n (\%) & $52(46.8)$ & $43(44.8)$ & 0.767 \\
\hline CVD, n (\%) & $47(42.3)$ & $54(56.3)$ & 0.046 \\
\hline Current smokers, n (\%) & $59(53.2)$ & $68(70.8)$ & 0.009 \\
\hline Past smokers, n (\%) & $8(7.2)$ & $15(15.6)$ & 0.055 \\
\hline Never smoked, n (\%) & 44 (39.6) & $13(13.5)$ & $<0.001$ \\
\hline Rutherford 4, n (\%) & $78(70.3)$ & $34(35.4)$ & $<0.001$ \\
\hline Rutherford 5, n (\%) & $33(29.7)$ & $62(64.6)$ & $<0.001$ \\
\hline Ankle Brachial Index & 0.645 & 0.55 & $<0.001$ \\
\hline $\begin{array}{l}\text { Total cholesterol, mg/ } \\
\text { dL }\end{array}$ & 215.582 & 223.513 & 0.011 \\
\hline LDL cholesterol, mg/dL & 107.898 & 118.067 & $<0.001$ \\
\hline Triglycerides, mg/dL & 172.009 & 172.854 & 0.475 \\
\hline Glucose, mg/dL & 127.611 & 128.441 & 0.539 \\
\hline $\mathrm{HbA} 1 \mathrm{C}, \%$ & 8.919 & 8.857 & 0.519 \\
\hline $\mathrm{eGFR} \mathrm{mL} / \mathrm{min} / 1.73 \mathrm{~m}^{2}$ & 72.489 & 73.24 & 0.611 \\
\hline Omentin-1 ng/mL & 31.339 & 26.672 & $<0.001$ \\
\hline
\end{tabular}

$B M I$ Body Mass Index, HBP High Blood Pression, HCHOL Hypercholesterolemia, $C A D$ Coronary Artery Disease, CVD Cerebrovascular Disease, $L D L$ low-density lipoprotein, eGFR estimated glomerular filtration rate. Statistical test performed with Student's t-test or with Chi square test, when appropriate.

linked to patient's genetic characteristics [26, 28-30], many linked metabolic and inflammatory parameters $[17,26,31-34]$. Among the possible candidates, the pathways linked to adipose tissue represent a promising field of study. In particular, adipokines have been extensively studied and a strong relationship between these bioactive molecules and the mechanisms underlying vascular complications of T2DM [26]. In this scenario, omentin-1 could be an ideal biomarker.

\section{Study findings}

The most important result of this study is that baseline omentin-1 levels correlate with the incidence of MACE during the period following LER in T2DM patients with PAD and with CLTI. Patients with lower omentin-1 levels had more myocardial infarctions, strokes and deaths. Amongst the explanations for our results, compelling evidence exists that demonstrates an inverse relationship between omentin-1 levels and some traditional risk factors for diabetic complications, including the amount and distribution of adipose tissue and glycemic control [35, 36]. In this sense, it is possible that reduced omentin-1 levels indirectly influenced the outcomes of our population, through the action of other risk factors. However, we did not observe differences in terms of BMI and glycemic balance in patients who had MACE compared to patients who did not. An additional possible explanation is that omentin-1 per se is a direct cardiovascular risk factor. This suggestion is in line with several previous evidences which demonstrate that omentin-1 levels are inversely correlated with the presence of CAD [8]. Indeed, omentin-1 levels are inversely related to the presence and extent of coronary artery atherosclerosis. Moreover, omentin-1 is inversely associated with intimamedia thickness of the common carotid artery in high risk T2DM patients [37]. Furthermore, the serum levels of this protein are independently correlated with carotid atherosclerosis and the presence of carotid plaque, increasing the risk of stroke [38-40]. Accordingly, in our cohort, omentin-1 levels significantly decreased not only in the composite MACE outcome, but also in the three distinct adverse events-myocardial infarction, stroke and death-strengthening our findings further. An additional interesting result of our study, emerging from the ROC and Kaplan-Meier curve analysis, is that cut-off values exist identifying higher risk patients that could develop early vascular complication. This could allow physicians to design a personalized follow-up, based on omentin-1 levels before LER procedure.

The molecular mechanisms underlying the effects observed could be numerous. Omentin-1 can determine several important protective effects on the vascular system through nitric oxide, Akt and the AMP-activated protein kinase pathways [41]. In particular, by reducing endothelial dysfunction [42], oxidative stress and neointimal proliferation [43]. Omentin-1 can reduce the atherosclerotic process and the development of the myocardial infarction itself [44].

A further finding of this study is that baseline omentin-1 levels correlate with the incidence of MALE during the follow-up period. This result is of particular interest in T2DM patients frequently facing numerous complications associated to PAD during their clinical history. One of the possible explanations can be found in the initial stratification that demonstrates how omentin-1 levels correlate with PAD severity, in terms of ABI and Rutherford staging, which is in agreement with previous data [16]. The new and most interesting result is that the prospective nature of the study allows assigning a predictive significance to the initial omentin-1 levels. Additionally, multivariate analyzes confirm an effect independent of other vascular risk factors, such as smoking or increased LDL-C. 
Table 5 Multivariable logistic regression for MALE

\begin{tabular}{|c|c|c|c|c|c|c|c|}
\hline & Coef & St.Err & t-value & p-value & [95\% Conf & Interval] & Sig \\
\hline Age & 0.000 & 0.004 & 0.07 & 0.947 & -0.007 & 0.007 & \\
\hline Male sex & 0.037 & 0.075 & 0.49 & 0.623 & -0.112 & 0.186 & \\
\hline $\mathrm{HBP}$ & 0.034 & 0.070 & 0.49 & 0.625 & -0.104 & 0.172 & \\
\hline $\mathrm{HCHOL}$ & -0.018 & 0.064 & -0.28 & 0.779 & -0.144 & 0.108 & \\
\hline CAD & -0.024 & 0.064 & -0.37 & 0.714 & -0.150 & 0.103 & \\
\hline CVD & 0.126 & 0.065 & 1.93 & 0.055 & -0.002 & 0.253 & $*$ \\
\hline Current smokers & -0.089 & 0.105 & -0.84 & 0.400 & -0.297 & 0.119 & \\
\hline Past smokers & 0.000 & & & & & & \\
\hline Never smoked & -0.220 & 0.120 & -1.83 & 0.068 & -0.456 & 0.017 & * \\
\hline $\mathrm{ABI}$ & -0.208 & 0.303 & -0.69 & 0.493 & -0.806 & 0.390 & \\
\hline LDL-C & 0.004 & 0.003 & 1.55 & 0.123 & -0.001 & 0.009 & \\
\hline FPG & 0.006 & 0.003 & 1.77 & 0.078 & -0.001 & 0.012 & $*$ \\
\hline $\mathrm{HbA} 1 \mathrm{C}$ & -0.068 & 0.046 & -1.49 & 0.137 & -0.159 & 0.022 & \\
\hline Omentin-1 & -0.026 & 0.007 & -3.56 & $<0.001$ & -0.041 & -0.012 & $* * *$ \\
\hline Constant & 0.751 & 0.778 & 0.96 & 0.336 & -0.783 & 2.285 & \\
\hline Mean dependent var & 0.464 & & SD dependent var & & 0.500 & & \\
\hline R-squared & 0.261 & & Number of obs & & 207.000 & & \\
\hline F-test & 5.241 & & Prob $>F$ & & 0.000 & & \\
\hline Akaike crit. (AIC) & 264.806 & & Bayesian crit. (BIC) & & 311.464 & & \\
\hline
\end{tabular}

*** $p<0.01,{ }^{* *} p<0.05,{ }^{*} p<0.1$

\section{Study limitations}

Amongst the limitations of our study, the relatively small, single-center patient cohort and the impossibility to establish whether the results are replicable in a larger number of patients. Furthermore, it is unfeasible to determine whether omentin-1 levels play a direct role on the vascular risk of our cohort or if it is only an epiphenomenon. However, the aim of the investigation was to explore a risk stratification biomarker and, in this perspective, the study design was appropriate. A further limitation is that the association between statin therapy and omentin-1 levels, which may have affected the LDL-C target during follow-up, has not been evaluated. Furthermore, there are non-univocal data in the literature on the role of omentin-1 on cardiovascular risk factors. In fact, baseline omentin-1 levels have been associated with intima-media thickness in a diabetic population [45]. However, in this specific study, the presence of PAD was an exclusion criterion and it is not possible to make a comparison with our data. Moreover, in a large population, omentin-1 levels have been shown to be associated with stroke risk [12]. However, there were many differences in terms of race, BMI, metabolic status, follow-up and outcomes compared to our study. There are also data demonstrating an association between omentin-1 levels and cardiovascular events [46]. However, in this population only a quarter of the patients were diabetic and there were no differences related to the presence of diabetes.
Furthermore, we have not found a significant association between MACE and previous CAD or CVD. Although several previous data confirm that an association between polyvascular atherosclerotic disease and the incidence of MACE does exist [47], we have not found this relationship in our diabetic population. This could partly be explained by the fact that the study population was exclusively composed of diabetic patients. In this scenario it is possible to hypothesize that the presence of T2DM in all patients is a more relevant risk factor than the previous CAD or CVD and that the influence of previous cardiovascular events in the incidence of MACE does not emerge. However, this conclusion is purely speculative and requires further confirmation on larger populations. Finally, an accurate analysis on the relationship between localization of initial arterial stenosis, restenosis and MALE has not been performed. The restrictive selection criteria, also excluding 17 patients where revascularization failed, reduced bias.

\section{Conclusion}

In conclusion, this study demonstrated that baseline levels of omentin-1 correlate with the onset of vascular complications, in particular MACE and MALE, after LER in T2DM patients with PAD and CLTI. Further investigations on a larger sample of patients are needed to confirm our findings. 


\section{Supplementary information}

Supplementary information accompanies this paper at https://doi. org/10.1186/s12933-020-01151-z.

Additional file 1: Table S1. Multivariable logistic regression for Death. Table S2. Multivariable logistic regression for CAD. Table S3. Multivariable logistic regression for CVD.

\section{Abbreviations}

ABI: Ankle/brachial index; BMI: Body mass index; CAD: Coronary artery disease; CLTI: Chronic limb-threatening ischemia; CVD: Cerebrovascular disease; eGFR Estimated glomerular filtration rate; LDL-C: Low-density lipoprotein cholesterol; LER: Lower limb revascularization; MACE: Major adverse cardiovascular events; MALE: Major adverse limb events; PAD: Peripheral artery disease; ROC Receiver operating characteristics; T2DM: Type 2 diabetes mellitus; US: Ultrasound; WIfl: Wound, ischemia, foot infection.

\section{Acknowledgements}

The authors are grateful to Franziska Lohmeyer for her English language assistance.

\section{Guarantor's statement}

Dr. Andrea Flex is the guarantor of this work and, as such, had full access to all the data in the study and takes responsibility for the integrity of the data and the accuracy of the data analysis.

\section{Authors' contributions}

FB and AF participated in the design of the study, performed data analysis and reviewed the manuscript. FA, ALC and EN carried out the immunoassays. MMR, DP, AS and MF participated in the design of the study and performed statistical analyses. AC and RI performed the endovascular procedures. RL and AF conceived the study, participated in its design and coordination and helped draft the manuscript. All authors read and approved the final manuscript.

\section{Funding}

Not applicable.

\section{Availability of data and materials}

The datasets generated during the current study are available from the corresponding author on reasonable request.

\section{Ethics approval and consent to participate}

The study was approved by the Ethics Committee of the Fondazione Policlinico Universitario A. Gemelli IRCCS and adhered to the principles of the Declaration of Helsinki. All the individuals agreed to participate in the study and gave informed consent.

\section{Consent for publication}

All authors have read the paper and agree that it can be published.

\section{Competing interests}

The authors declare that they have no competing interests.

\section{Author details}

${ }^{1}$ Fondazione Policlinico Universitario A. Gemelli IRCCS, Rome, Italy. ${ }^{2}$ Internal Medicine and Vascular Diseases Unit, Rome, Italy. ${ }^{3}$ Department of Translational Medicine and Surgery, Laboratory of Vascular Biology and Genetics, Rome, Italy. ${ }^{4}$ Department of Radiology, Rome, Italy. ${ }^{5}$ Ospedale San Giovanni Battista-ACISMOM, Rome, Italy. ${ }^{6}$ Università Cattolica del Sacro Cuore, Rome, Italy. ${ }^{7}$ Angiology Unit, Rome, Italy. ${ }^{8}$ Diabetology Unit, Rome, Italy. ${ }^{9}$ Department of Internal Medicine, Fondazione Policlinico Universitario A. Gemelli IRCCS, Catholic University School of Medicine, Largo Francesco Vito, 1, 00168 Rome, Italy.

Received: 22 May 2020 Accepted: 1 October 2020

Published online: 07 October 2020
References

1. Association AD. Peripheral arterial disease in people with diabetes. Diabetes Care. 2003:26(12):3333-41.

2. Anand SS, Caron F, Eikelboom JW, Bosch J, Dyal L, Aboyans V, Abola MT, Branch KRH, Keltai K, Bhatt DL, et al. Major adverse limb events and mortality in patients with peripheral artery disease: the COMPASS trial. J Am CollCardiol. 2018;71(20):2306-15.

3. Aboyans V, Ricco JB, Bartelink MEL, Björck M, Brodmann M, Cohnert T, Collet JP, Czerny M, De Carlo M, Debus S, et al. 2017 ESC Guidelines on the Diagnosis and Treatment of Peripheral Arterial Diseases, in collaboration with the European Society for Vascular Surgery (ESVS): document covering atherosclerotic disease of extracranial carotid and vertebral, mesenteric, renal, upper and lower extremity arteriesEndorsed by: the European Stroke Organization (ESO)The Task Force for the Diagnosis and Treatment of Peripheral Arterial Diseases of the European Society of Cardiology (ESC) and of the European Society for Vascular Surgery (ESVS). Eur Heart J. 2018;39(9):763-816.

4. Baumgartner I, Norgren L, Fowkes FGR, Mulder H, Patel MR, Berger JS, Jones WS, Rockhold FW, Katona BG, Mahaffey K, et al. Cardiovascular outcomes after lower extremity endovascular or surgical revascularization: the EUCLID trial. J Am CollCardiol. 2018;72(14):1563-72.

5. Ferraresi R, Centola M, Ferlini M, Da Ros R, Caravaggi C, Assaloni R, Sganzaroli A, Pomidossi G, Bonanomi C, Danzi GB. Long-term outcomes after angioplasty of isolated, below-the-knee arteries in diabetic patients with critical limb ischaemia. Eur J Vasc Endovasc Surg. 2009;37(3):336-42.

6. Yamawaki H. Vascular effects of novel adipocytokines: focus on vascular contractility and inflammatory responses. Biol Pharm Bull. 2011;34(3):307-10.

7. De Jager SC, Pasterkamp G. Atheroprotective properties of human Omentin-1 in experimental atherosclerosis. Cardiovasc Res. 2016:110(1):1-3.

8. Du Y, Ji Q, Cai L, Huang F, Lai Y, Liu Y, Yu J, Han B, Zhu E, Zhang J, et al. Association between omentin-1 expression in human epicardial adipose tissue and coronary atherosclerosis. Cardiovasc Diabetol. 2016;15:90.

9. Elsaid NH, Sadik NA, Ahmed NR, Fayez SE, Mohammed NAE. Serum omentin-1 levels in type 2 diabetic obese women in relation to glycemic control, insulin resistance and metabolic parameters. J Clin Transl Endocrinol. 2018:13:14-9.

10. Hayashi M, Morioka T, Hatamori M, Kakutani Y, Yamazaki Y, Kurajoh M, Motoyama K, Mori K, Fukumoto S, Shioi A, et al. Plasma omentin levels are associated with vascular endothelial function in patients with type 2 diabetes at elevated cardiovascular risk. Diabetes Res Clin Pract. 2019;148:160-8.

11. Ohashi K, Shibata R, Murohara T, Ouchi N. Role of anti-inflammatory adipokines in obesity-related diseases. Trends Endocrinol Metab. 2014;25(7):348-55

12. Menzel J, di Giuseppe R, Biemann R, Wittenbecher C, Aleksandrova K, Pischon T, Fritsche A, Schulze MB, Boeing H, Isermann B, et al. Omentin-1 and risk of myocardial infarction and stroke: Results from the EPIC-Potsdam cohort study. Atherosclerosis. 2016;251:415-21.

13. Watanabe K, Watanabe $R$, Konii $H$, Shirai $R$, Sato K, Matsuyama TA, Ishibashi-Ueda H, Koba S, Kobayashi Y, Hirano T, et al. Counteractive effects of omentin-1 against atherogenesist. Cardiovasc Res. 2016;110(1):118-28.

14. Zhong X, Zhang HY, Tan H, Zhou Y, Liu FL, Chen FQ, Shang DY. Association of serum omentin-1 levels with coronary artery disease. Acta Pharmacol Sin. 2011;32(7):873-8.

15 Lis I, Pelczyńska M, Miller-Kasprzak E, Mądry E, Bogdański P. Association of serum omentin concentration with anthropometric, physiological, and biochemical parameters in obese individuals. Nutrition. 2020;79:110866.

16. Biscetti F, Nardella E, Bonadia N, Angelini F, Pitocco D, Santoliquido A, Filipponi M, Landolfi R, Flex A. Association between plasma omentin-1 levels in type 2 diabetic patients and peripheral artery disease. Cardiovasc Diabetol. 2019;18(1):74

17. Biscetti F, Ferraro PM, Hiatt WR, Angelini F, Nardella E, Cecchini AL, Santoliquido A, Pitocco D, Landolfi R, Flex A. Inflammatory cytokines associated with failure of lower-extremity endovascular revascularization (LER): a prospective study of a population with diabetes. Diabetes Care. 2019;42(10):1939-45.

18. Young MJ, Breddy JL, Veves A, Boulton AJ. The prediction of diabetic neuropathic foot ulceration using vibration perception thresholds. A prospective study. Diabetes Care. 1994;17(6):557-60. 
19. Young MJ, Boulton AJ, MacLeod AF, Williams DR, Sonksen PH. A multicentre study of the prevalence of diabetic peripheral neuropathy in the United Kingdom hospital clinic population. Diabetologia. 1993;36(2):150-4.

20. Ewing DJ, Clarke BF. Diagnosis and management of diabetic autonomic neuropathy. Br Med J. 1982;285(6346):916-8.

21. Suggested standards for reports dealing with lower extremity ischemia. Prepared by the Ad Hoc Committee on Reporting Standards, Society for Vascular Surgery/North American Chapter, International Society for Cardiovascular Surgery. J Vasc Surg. 1986; 4(1):80-94.

22. Eikelboom JW, Connolly SJ, Bosch J, Dagenais GR, Hart RG, Shestakovska O, Diaz R, Alings M, Lonn EM, Anand SS, et al. Rivaroxaban with or without aspirin in stable cardiovascular disease. N Engl J Med. 2017;377(14):1319-30.

23. Thukkani AK, Kinlay S. Endovascular intervention for peripheral artery disease. Circ Res. 2015;116(9):1599-613.

24. Sacks D, Marinelli DL, Martin LG, Spies JB. Committee SoIRTA: Reporting standards for clinical evaluation of new peripheral arterial revascularization devices. J Vasc Interv Radiol. 2003;14(9 Pt 2):S395-404.

25. Hazarika S, Annex BH. Biomarkers and genetics in peripheral artery disease. ClinChem. 2017;63(1):236-44.

26. Biscetti F, Nardella E, Cecchini AL, Flex A, Landolfi R. Biomarkers of vascular disease in diabetes: the adipose-immune system cross talk. Intern Emerg Med. 2020;15(3):381-93.

27. Doshi R, Changal KH, Gupta R, Shah J, Patel K, Desai R, Meraj P, Syed MA, Sheikh AM. Comparison of outcomes and cost of endovascular management versus surgical bypass for the management of lower extremities peripheral arterial disease. Am J Cardiol. 2018;122(10):1790-6.

28. Biscetti F, Straface G, Angelini F, Pitocco D, Landolfi R, Flex A. Association of RANK/RANKL/OPG gene polymorphisms with risk of peripheral arterial disease (PAD) and critical limb ischemia in the general Italian population. Meta Gene. 2017;11:85-90.

29. Biscetti F, Porreca CF, Bertucci F, Straface G, Santoliquido A, Tondi P, Angelini F, Pitocco D, Santoro L, Gasbarrini A, et al. TNFRSF11B gene polymorphisms increased risk of peripheral arterial occlusive disease and critical limb ischemia in patients with type 2 diabetes. Acta Diabetol. 2014;51(6):1025-32

30. Flex A, Gaetani E, Angelini F, Sabusco A, Chillà C, Straface G, Biscetti F, Pola $P$, Castellot JJ, Pola R. Pro-inflammatory genetic profiles in subjects with peripheral arterial occlusive disease and critical limb ischemia. J Intern Med. 2007;262(1):124-30.

31. Biscetti F, Bonadia N, Santini F, Angelini F, Nardella E, Pitocco D, Santoliquido A, Filipponi M, Landolfi R, Flex A. Sortilin levels are associated with peripheral arterial disease in type 2 diabetic subjects. Cardiovasc Diabetol. 2019;18(1):5.

32. Giovannini S, Tinelli G, Biscetti F, Straface G, Angelini F, Pitocco D, Mucci L, Landolfi R, Flex A. Serum high mobility group box-1 and osteoprotegerin levels are associated with peripheral arterial disease and critical limb ischemia in type 2 diabetic subjects. Cardiovasc Diabetol. 2017;16(1):99.

33. Biscetti F, Straface G, Pitocco D, Angelini F, Tinelli G, Landolfi R, Flex A. Fibroblast growth factor 23 serum level in type 2 diabetic italian subjects with peripheral arterial disease and critical limb ischemia. Eur Rev Med Pharmacol Sci. 2016;20(19):4048-54.

34. Biscetti F, Pitocco D, Straface G, Zaccardi F, de Cristofaro R, Rizzo P, Lancellotti S, Arena V, Stigliano E, Musella T, et al. Glycaemic variability affects ischaemia-induced angiogenesis in diabetic mice. ClinSci. 2011;121(12):555-64.

35. Rathwa N, Patel R, Pramanik Palit S, Jadeja SD, Narwaria M, Ramachandran AV, Begum R. Circulatory Omentin-1 levels but not genetic variants influence the pathophysiology of Type 2 diabetes. Cytokine. 2019;119:144-51.

36. Yang RZ, Lee MJ, Hu H, Pray J, Wu HB, Hansen BC, Shuldiner AR, Fried SK, McLenithan JC, Gong DW. Identification of omentin as a novel depot-specific adipokine in human adipose tissue: possible role in modulating insulin action. Am J Physiol Endocrinol Metab. 2006;290(6):E1253-1261.

37. Nishimura M, Morioka T, Hayashi M, Kakutani Y, Yamazaki Y, Kurajoh M, Mori K, Fukumoto S, Shioi A, Shoji T, et al. Plasma omentin levels are inversely associated with atherosclerosis in type 2 diabetes patients with increased plasma adiponectin levels: a cross-sectional study. Cardiovasc Diabetol. 2019;18(1):167.

38. Liu R, Wang X, Bu P. Omentin-1 is associated with carotid atherosclerosis in patients with metabolic syndrome. Diabetes Res Clin Pract. 2011;93(1):21-5.

39. Yoo HJ, Hwang SY, Hong HC, Choi HY, Yang SJ, Seo JA, Kim SG, Kim NH, Choi KM, Choi DS, et al. Association of circulating omentin-1 level with arterial stiffness and carotid plaque in type 2 diabetes. Cardiovasc Diabetol. 2011;10:103.

40. Xu T, Li Y, Su Y, Zuo P, Gao Z, Ke K. Serum omentin-1 and risk of one-year mortality in patients with ischemic stroke. Clin Chim Acta. 2020;505:167-71.

41. Cheng X. Elucidating the pathophysiological significance of circulating omentin levels: Is higher better? Atherosclerosis. 2016;251:522-4.

42. Maruyama S, Shibata R, Ohashi K, Ohashi T, Daida H, Walsh K, Murohara T, Ouchi N. Adiponectin ameliorates doxorubicin-induced cardiotoxicity through Akt protein-dependent mechanism. J Biol Chem. 2011;286(37):32790-800.

43. Uemura Y, Shibata R, Kanemura N, Ohashi K, Kambara T, Hiramatsu-Ito M, Enomoto T, Yuasa D, Joki Y, Matsuo K, et al. Adipose-derived protein omentin prevents neointimal formation after arterial injury. FASEB J. 2015;29(1):141-51.

44. Kataoka Y, Shibata R, Ohashi K, Kambara T, Enomoto T, Uemura Y, Ogura Y, Yuasa D, Matsuo K, Nagata T, et al. Omentin prevents myocardial ischemic injury through AMP-activated protein kinase- and Akt-dependent mechanisms. J Am Coll Cardiol. 2014;63(24):2722-33.

45. Yoo HJ, Hwang SY, Hong HC, Choi HY, Yang SJ, Lee KW, Nam MS, Park YS, Woo JT, Kim YS, et al. Implication of circulating omentin-1 level on the arterial stiffening in type 2 diabetes mellitus. Endocrine. 2013;44(3):680-7.

46. Saely CH, Leiherer A, Muendlein A, Vonbank A, Rein P, Geiger K, Malin C, Drexel H. High plasma omentin predicts cardiovascular events independently from the presence and extent of angiographically determined atherosclerosis. Atherosclerosis. 2016;244:38-433.

47. Miao B, Hernandez AV, Alberts MJ, Mangiafico N, Roman YM, Coleman $\mathrm{Cl}$. Incidence and predictors of major adverse cardiovascular events in patients with established atherosclerotic disease or multiple risk factors. J Am Heart Assoc. 2020;9(2):e014402.

\section{Publisher's Note}

Springer Nature remains neutral with regard to jurisdictional claims in published maps and institutional affiliations. 